\title{
Clinical Uses and Toxicity of Aloe vera: An Evidence-Based Comprehensive Retrospective Review (2007-2017)
}

\author{
Ahmed Muhammad Ibrahim ', Hussain Al Sadah', Rizwan Ahmad ${ }^{1}$, Niyaz Ahmad ${ }^{2,}$, Atta Abbas Naqvi ${ }^{3}$
}

\section{Ahmed Mohammed Aljamea ${ }^{1}$, Hussain Mazin Alsadah ${ }^{1}$, Rizwan Ahmad2*, Niyaz Ahmad ${ }^{3}$, Atta Abbas $\mathrm{Naqvi}^{4}$}

'College of Clinical Pharmacy, Imam Abdulrahman Bin Faisal University, Dammam, SAUDI ARABIA

${ }^{2}$ Natural Products and Alternative Medicines, College of Clinical Pharmacy, Imam Abdulrahman Bin Faisal University, Dammam, SAUDI ARABIA.

${ }^{3}$ Department of Pharmaceutics, College of Clinical Pharmacy, Imam Abdulrahman Bin Faisal University, Dammam, SAUDI ARABIA. ${ }^{4}$ Department of Pharmacy practice, College of Clinical Pharmacy, Imam Abdulrahman Bin Faisal University, Dammam, SAUDI ARABIA.

Correspondence

Dr. Rizwan Ahmad

Natural Products and Alternative Medicines, College of Clinical Pharmacy, Imam Abdulrahman Bin Faisal University, Dammam, Saudi Arabia.

Phone no : 00966549831835

E-mail: rizvistar_36@yahoo.com,

History

- Submission Date: 30-07-2018;

- Review completed: 03-09-2018.

- Accepted Date: 19-12-2018

DOI : 10.5530/pj.2019.11.66

Article Available online

http://www.phcogj.com/v11/i2

Copyright

(C) 2019 Phcog.Net. This is an openaccess article distributed under the terms of the Creative Commons Attribution 4.0 International license.

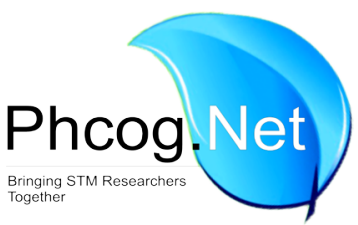

\begin{abstract}
Background: Aloe vera (AV), mostly known as succulents, or the healing plant of the genus Aloe of Liliaceae family. It contains large range of vitamins, amino acids, antiseptic, antiinflammatory, and sulfur compounds to control and eliminate mold, bacteria, viruses; however, AV toxicity is most of the times described poorly among AV consumers. Aim of the Study: To report and highlight AV clinical uses and toxicity cases to compare and highlight its therapeutic as well toxic profile. Materials and Methods: AV cases were gathered from databases such as Google Scholar, PubMed, Web of Science, Scopus, and E-Resource Portal of Imam Abdulrahman bin Faisal University using the keywords, i.e., AV case report, AV toxicity, hepatitis, clinical trials about $A V$, interactions, the current uses of $A V$, etc. Results: Ten cases met the eligibility criteria where the toxicities were mostly associated with the usage of AV except the intended use, i.e., to be administered topically or AV capsules ingestion or as a drinkable solutions. Major symptoms observed in these cases were related to hepatocytes inflammation (hepatitis), fatigue, nausea, vomiting, thyroid dysfunction, abdominal discomfort, and diarrhea along with severe weight loss. These results were not associated with a specific age; however they were more predominant in female gender. Conclusion: AV should be taken within normal/specified dose range which can only be achieved through asking an herbal specialist, and in approved suitable dosage form which is topical.

Key words: Acemannan, Aloe vera, Cosmetics, Hepatitis, Toxicity
\end{abstract}

\section{INTRODUCTION}

Liliaceae, a glycosidic plant family, is well-known for its cosmetically used applications, and for its chemical similarities despite its morphological differences. Aloe barbadensis miller, usually referred to as Aloe vera (AV) synonym; the healing plant and the silent healer belongs to the family Liliaceae, a family that has $>700$ species and is divided into 15 genus, known for its components of large amount of vitamins. AV is a perennial succulent green plant which provides a gelatin-like extract that can be used cosmetically. The plant originally grew in Southern and Eastern Africa and was introduced into Northern Africa, and naturalized in the Mediterranean region and other countries around the globe. ${ }^{1}$ It is the oldest herbal plant which has long been used for several diseases. It has leaves where each leaf consists of two parts, outer green rind and an inner clear pulp. The pulp which is mucilaginous is the most widely therapeutically used portion of the plant as an emollient. It is showing perfect growing in marginal to submarginal soils which are having low fertility, high $\mathrm{pH}$, and high amount of salts. AV as a plant is well-known in pharmaceutical ingredient as well as chemical industries due to its contents that are rich in vitamins such as vitamin- $B_{12}$, vitamin- $C$, vitamin-A, vitamin-E, and folic acid. Similarly, in terms of amino acids, it has $>10$ nonessential and 8 essential amino acids. It has several major chemical constituents (aloins, nataloins, barbaloin, aloe-emodin, octapeptide, and aloesin), and six antiseptic agents such as lupeol, salicylic acid, urea nitrogen, cinnamic acid, phynol, and sulfur for killing or controlling the mold, bacteria, and viruses by using it in specific concentrations. It has $>3$ anti-inflammatory such as polyunsaturated fatty acids, cholesterol, betasitosterol, carboxypeptidase enzyme, as well as bradykinase enzyme which exerts a relieving action in pains, inflammatory swelling, burns, cut inflammations, and is used for some allergic reactions. AV contains about 24 polypeptides to help and control the immunity in some immune disorders. Regarding cancerous abnormal growth they work as antineoplastic agent because of some active chemicals like aloe-emodin that exhibits inhibitory action against some types of cancer such as ascites carcinoma cell, acute myeloid leukemia, and acute lymphocytes leukemia cancerous cells. ${ }^{2} \mathrm{AV}$ has a high concentration of mannose 6-phosphate which is known by its well-reputed action in the immune system. AV extraction leads to isolation of some of the significant chemical compounds such as plusiso-aloesin
Cite this article: Ibrahim AM, Al Sadah H, Ahmad R, Ahmad N, Naqvi AA. Clinical uses and toxicity of Aloe vera: An evidence-based comprehensive retrospective review (2007-2017). Phcog Pharmacog J. 2019;11(2):424-8. 
(anti-oxidative) from its leaf, polysaccharides and phenolic chemicals, such as anthraquinones glycosides, i.e., aloin A and B that are involved in every action related to $\mathrm{AV}^{3}$

The use of AV may result mild-to-moderate side effects depending on the way and dosage used. Mostly, the people self-treat their self for minor wounds or burn, whereby they put the leaves or leaf pulp directly over the site of injury and this may lead to toxicity or complications including allergy. ${ }^{4}$ Thus, a proper direction while using AV is very important in this regard. Some of the studies have reported carcinogenic effect in large intestine for AV in either sex, following an oral ingestion. ${ }^{5}$ Similar studies have reported a potential kidney and liver damage, with kidney failure and hepatitis, associated with severe ingestion of AV. ${ }^{6}$ Even limited doses if taken improperly are associated with diarrhea, electrolyte imbalance, dermatitis, kidney dysfunction, hepatitis, hypokalemia, erythema, hypersensitivity, and photo toxicity with topical use. ${ }^{7}$ During in vitro studies for preclinical tests, renal tubular pigmentation, proliferative mesenteric lymph node, and nephropathy were revealed, in tested animals. ${ }^{3} \mathrm{AV}$ has dose-related hyperplastic effect in the stomach, a small and large intestine and lymph nodes which may lead to neoplasm with continuous further use as well as a depressing body weight due to an interaction with thyroid gland activity and body metabolism. ${ }^{8}$ Although most of the ancient studies of alternative medicines is using the positive benefits of AV with the claim of having no adverse effects associated with its use; however, the recent researches have proved many side effects of AV resulting due to misuse and wrong dose or dosage form etc. ${ }^{9}$

For therapeutic purposes, the herb is very popular with widespread uses of; as skin healer, source of vitamin, digestion improver, antiviral, immune booster, nerve tonic, antibacterial, moisturizer, sun protective, antiaging, stretch mark remover, acne killer, and strong detoxifier if used in a proper way. ${ }^{10}$ This study aims to review all the available reported clinical cases for AV toxicity, and to observe as well highlight the factors leading toward toxicity of this plant.

\section{MATERIALS AND METHODS}

\section{Databases searched}

The relevant literature was searched using different databases such as Central Library of Imam Abdulrahman bin Faisal University, Science Direct, Web of Science, PubMed, and Google Scholar. In addition, journals such as Journal of Traditional and Complementary Medicine, Journal of Environmental Science, and health and global journal of pharmaceutical and biological sciences, Journal of Ethnopharmacology, frontiers in ethnopharmacology, and books such as "AV Nature's Soothing Healer" and "AV: Nature's Silent Healer."

\section{Keywords searched}

$\mathrm{AV}$, toxicity cases of $\mathrm{AV}$, clinical uses of $\mathrm{AV}$, toxicity of $\mathrm{AV}$, clinical cases reported for $\mathrm{AV}$, case reports of $\mathrm{AV}$ intoxication, $\mathrm{AV}$ intoxication, cases of AV poisoning, and acute hepatitis intoxication of AV.

\section{Review period}

This article used an extensive in-depth retrospective search from 2007 to 2017 consisting of 10 years for relevant literature as mentioned above.

\section{Inclusion criteria}

Clinical cases included in this review are only associated to/reported in human subjects. Any adverse effects or toxicity resulted due to use of AV in conventional system or herbal system as well as any use and side or adverse effect related to intentional or unintentional ingestion of AV was included in the study. Furthermore, the toxicity or overdose associated with the use of any part of the plant AV, i.e., leaves, flowers, fruits, and seeds were also included.

\section{Exclusion criteria}

Any clinical case reported in animal or any in vitro study was excluded from the study. Similarly, any case reporting traditional or general uses of $\mathrm{AV}$ rather than evidence based, i.e., any clinical case reported to hospital emergency or clinics were also excluded from the study.

\section{Search results}

The retrospective 10 years literature was searched and refined to the target of the study. A total of 10 articles matched the inclusion criteria and they are reported in the literature review section as below as well as in Table $1 .$.

\section{LITERATURE REVIEW}

All the relevant cases were collected, studied, analyzed, and reported after a broad literature review. The cases are presented below with respect to the year of publication.

\section{CLINICAL CASES REPORTED IN 2017}

\section{Small bowel serositis}

A 74-year-old male was presented in ER with signs of severe weight lost, frequent vomiting, and abdominal pain, after consuming excessive amount of $\mathrm{AV}$, for 10 days to cure cancer. Pathological examination revealed acute serositis of the small intestine with neutrophils. Following a resection, the small bowel loops were found dilated and obstructed by multiple greenish masses. The patient recovered without any complication after being discharged. ${ }^{11}$

\section{Acute liver failure due to the use of Aloe vera}

A case of 68-year-old female patient was presented in hospital with acute liver failure symptoms (jaundice, disorientation, abdominal pain, malaise, nausea, and vomiting). On investigation, it was revealed that the patient used herbal medication of AV. After discontinuation of the herbal medication, the liver returned to function normally and symptoms were resolved. ${ }^{12}$

\section{CLINICAL CASES REPORTED IN 2016}

\section{Aloe vera causing inflammatory hepatitis}

A case report for a 61-year-old female patient was presented in ER. The patient informed the ER that she had not taken any recent medication except AV. Examination tests revealed jaundice and abdominal pain, whereas the liver biopsy results showed inflammatory hepatitis. Three weeks later of discontinuation of $\mathrm{AV}$, she showed improve in the liver function..$^{13}$

\section{Hypothyroidism developed from Aloe vera}

A 56-year-oldfemale patient with reticular lichen planus lesion preferred to use AV juice instead of corticosteroids. No related effect was observed on the reticular lichen planus lesion with the use of plant; however, the plant developed uncontrolled hypothyroidism effect. On discontinuation of AV juice, the hypothyroidism effect was resolved. ${ }^{9}$

\section{CLINICAL CASES REPORTED IN 2014}

\section{Aloe vera gel caused hepatitis inflammation}

A 21-year obese female patient presented with the complication of nausea, vomiting, and abdominal discomfort. On history examination, she used $50 \mathrm{ml} \mathrm{AV}$ gel twice a day for months with a hope to reduce her weight. A tenderness with mild splenomegaly has been observed on her upper abdomen, whereas liver biopsy showed a continuous necrosis by the white blood cells (WBCs) filtration which is the clue of hepatitis 


\begin{tabular}{|c|c|c|c|c|c|c|}
\hline Cases years & Form used & Age & Gender & Clinical manifestations & Way of treatment & Cause of ingestion \\
\hline 2017 & Plant & 74 & Male & $\begin{array}{c}\text { Weight loss } \\
\text { Vomiting } \\
\text { Abdominal discomfort } \\
\text { Acute serositis }\end{array}$ & Upon cessation & Beating cancer \\
\hline 2017 & AV medication & 68 & Female & Liver failure symptoms & Upon cessation & - \\
\hline 2016 & AV medication & 61 & Female & $\begin{array}{c}\text { Jaundice } \\
\text { Abdominal discomfort } \\
\text { Hepatitis }\end{array}$ & Upon cessation & - \\
\hline 2016 & AV juice & 56 & Female & $\begin{array}{c}\text { Reticular lichen planus lesion } \\
\text { Hypothyroidism }\end{array}$ & Upon cessation & Reticular lichen planus lesion \\
\hline 2014 & AV gel & 21 & Female & $\begin{array}{c}\text { Nausea } \\
\text { Vomiting } \\
\text { Abdominal discomfort } \\
\text { Hepatitis }\end{array}$ & Upon cessation & Weight reduction \\
\hline 2014 & AV tablet & 57 & Female & Hepatitis & Upon cessation & - \\
\hline 2010 & AV powder & 62 & Female & $\begin{array}{c}\text { Hepatitis } \\
\text { Weakness } \\
\text { Fatigue }\end{array}$ & Upon cessation & - \\
\hline 2010 & AV extract & 55 & Female & Abdominal discomfort & Upon cessation & - \\
\hline 2007 & AV capsule & 73 & Female & Acute hepatitis & Upon cessation & Constipation \\
\hline 2007 & AV juice & 72 & Female & Dermatitis & Upon cessation & Pain relief \\
\hline
\end{tabular}

$\mathrm{AV}=$ Aloe vera

inflammation. Following a discontinuation of $\mathrm{AV}$ gel, the patient returned to normal. ${ }^{14}$

\section{Aloe vera tablet caused hepatitis inflammation}

A 57-year-old female patient took AV tablets containing $500 \mathrm{ml}$ of active ingredient plus vitamin $\mathrm{C}$ with zinc. She showed an autoimmune marker of hepatitis (there was a huge number of antibodies like antihepatitis $B$ surface antigen-Immunoglobulin G (HBs-IgG) and then liver biopsy showed a severe acute hepatitis. After abrupt stop of medications, the patient was healthy again..$^{15}$

\section{CLINICAL CASES REPORTED IN 2010}

\section{Aloe vera as a powder causes hepatitis}

A 62-year-old female patient with hepatitis symptoms, and a week history of fatigue and weakness reported to hospital. She had taken AV powder containing $420 \mathrm{mg}$ of an extract of AV for about 3 months. Liver biopsy confirmed hepatitis. Aloe extract was immediately discontinued, and the jaundice and hepatitis were resolved. ${ }^{16}$

\section{High dose of Aloe vera causes liver damage}

A 55-year-old female patient was presented to the hospital with 3 months history of abdominal discomfort. She had taken AV extracts in excessive dose for $>2$ months before she presented the symptoms. Great damage to the liver was detected by serology. Aloe extract was immediately discontinued. After 4 days, she visited again for laboratory tests, and the liver function was found normal. ${ }^{16}$

\section{CLINICAL CASES REPORTED IN 2007}

\section{Aloe vera capsule caused hepatitis inflammation}

A 73-year-old female was administered to the hospital for an acute hepatitis. Laboratory tests did not reveal the cause of the patient's disease; however, after an extensive medication history by a clinical pharmacist, it was revealed that she used oral AV capsules for constipation. She stopped the use of AV capsules which led to the return of liver markers to normal levels. ${ }^{17}$

\section{Allergy from Aloe vera}

A 72-year-old female presented in the clinic with dermatitis on the leg. She has been using self-made AV juice over the leg to relieve pain. Skin tests revealed that she had an allergic reaction to $\mathrm{AV} .{ }^{18}$

\section{DISCUSSION}

AV or Aloe barbadensis miller, a plant that belongs to genus Aloe of Liliaceae family. It is considered as one of the greatest source of vitamins and minerals used in Mesopotamia since 1750. Egyptian and Greek used the plant for skin infections and wound healing. ${ }^{6}$ With the advancement in science and research, it has been observed that AV may be toxic and produce a variety of severe effects. Although most of the adverse effects are easy to handle; however, the liver and kidney damage are fatal and may lead to failure of both organs. The symptoms are not differentiable on the basis of age; however, gender may play a significant role. In addition, the severity of symptoms depends on the way of administration whether it is ingested, injected, or topically used. ${ }^{5}$ Overall, topical use has been reported with very few side or adverse effect, but still may produce troublesome and irritating condition. With respect to general symptoms, the following have been reported with the use of AV plant. Skin problems Different conditions such as skin allergy, rashes after sun exposures, dermatitis, skin hardening, dryness, splitting, redness, burning, and yellow stain in the skin were reported in many people using topical latex or AV leaf or its pulp without a proper counseling or dosage. In cases mentioned above, it was found that $\mathrm{AV}$ juice may result allergic reaction. The patient was unaware of its symptoms severity and thus, they were using it in an uncontrolled way. However, it is also a fact that skin 
reactions occurs very rarely. Gastrointestinal tract (GIT) problems - Few of the times ingestion of AV may lead to local GIT symptoms such as severe diarrhea alongwith dehydration due to strong laxative action of $\mathrm{AV}$ and hence, electrolytes imbalances are observed. Studies showed that $\mathrm{AV}$ may increase the risk of arrhythmia perhaps because of severe loss of these minerals. ${ }^{19}$ Liver inflammation - - Among the toxicity cases reported, hepatitis is what AV exerts as a common adverse effect. The presence of various alkaloids in AV enhances hepatic enzymes as well as alcohol dehydrogenase activity. Such interference with detoxification mechanisms produces hepatic damage in hepatocytes. ${ }^{20}$ As per mentioned cases (literature review section), it is evident that taking AV supplementation, i.e., gel, tablets, or capsules, results acute hepatitis which is hepatocellular only; however, such hepatic damage is usually observed with long-term use of high doses of AV. ${ }^{15,21}$ Carcinogenic effect - Although AV has proved to be a good inducer for immunity through its action in bone marrow, where it increases WBCs production. However, various studies have reported that strange doses of $\mathrm{AV}$ may lead to abnormal growth/leukemia. ${ }^{22}$ Furthermore, some studies showed that AV constituents may be metabolized to mutagenic compounds with significant evidence for carcinogenicity. ${ }^{21}$ The severity of AV oral administration - Caution is needed during oral administration of $\mathrm{AV}$ as once it is ingested orally, some histopathological changes as well as structural alterations for various tissues may be seen due to oxidative radicals which indicates its toxicity. Colorectal cancer as well as dependency has been observed with oral use of $\mathrm{AV}$, hence various organizations have rejected the oral dose of AV due to its severe effects. Still, some of the studies favor the oral use of AV up to a dose of $50 \mathrm{mg} / \mathrm{kg}$ or below, without any effect on any organ and biochemical change. ${ }^{19,23}$ Miscellaneous Diseases such as serous tissue inflammation after excessive ingestion of $\mathrm{AV}$, weight loss, and weakness alongwith thyroid dysfunction, i.e., hypothyroidism has been reported for AV.

In contrast - AV is known to have a huge positive impact and is used clinically now-a-days for a variety of conditions in its approved dosage forms. AV possesses potential therapeutic chemicals with important therapeutic and pharmacological actions as discussed below.

Healing properties - AV best known as the healing plant, having a potential of fast healing action due to its ability of increasing collagen production, changing collagen compositions, induction of synthesis for hyaluronic acid, and dermatan sulfate in the granulation tissue which all together accelerates wound healing. Anti-inflammatory action $\mathrm{AV}$ works by reduction of prostaglandin- $\mathrm{E}_{2}$ and prevent its production from arachidonic acid through inhibition of cyclooxygenase enzyme. AV contains the novel anti-inflammatory compound, that is, specifically existing in the gel. An innovative product acemannan for AIDS patients - Acemannan is a polysaccharide found in the inner part of AV leaves. Acemannan has no toxicity and acts as an immnunoenhancer. Acemannan stimulates the immune system by stimulating monocytes, macrophages, phagocytosis, increases antibody production, enhances antiviral activity, and in patient with AIDS, produces defective human immunodeficiency virus (HIV) virus. ${ }^{24} \mathrm{AV}$ in cosmetics - AV is used in cosmetics due to the presence of polysaccharides with an effectiveness of reducing skin dryness through its moisturizing mechanism. Increasing the water amount in the stratum corneum can be seen in the $1^{\text {st }}$ week..$^{25}$ $\mathrm{AV}$ as polypharmacy - AV is usually considered safe when used as polypharmacy; however, it can have synergistic effects when used with herbs or drugs having a similar action to AV. To avoid any interaction, a complete information should be provided to the prescriber in order not to administer it to a patient already using any drugs or herbs as AV due to its multifunctional use may exert additive effects. ${ }^{26}$ Laxative effects - AV works through three mechanism; (i) Increasing intestinal water content, (ii) Stimulation of the mucosa to secrete, and (iii) Increasing intestinal peristalsis strongly and these effects of AV are mediated through anthraquinones glycosides present in the plant. Antiseptic effect - Lupeol, salicylic acid, cinnamic acid, phenols, and sulfur are the major compounds responsible for $\mathrm{AV}$ antiseptic role. AV has been reported to kill many of the types of microorganism including bacteria and fungi. AV for topical therapeutic purposes - Since AV contains several topical administrable dosage forms, i.e., gel that has immune inductive as well as anti-inflammatory effect, thus microorganism topical invasions is better treated by $\mathrm{AV}$ due to its potent bactericidal action. ${ }^{27}$ Miscellaneous - Anti-aging property due to the presence of mucopolysaccharides which moistens and improving skin elasticity, burn recovery through reduction of burn's ischemic effects, as well as induction and modulation of the immune system are the properties reported for AV. ${ }^{19,22}$ Some studies revealed anti-thromboxane effect for AV in animal models alongwith a property to maintain hemostasis in vascular endothelium. ${ }^{10}$ The ability to inhibit the release of oxygen-reactive species by AV gel-extract ${ }^{3}$ imparts the potential to treat chronic ulcers, eczema, and pruritus vulvae. ${ }^{19}$ In addition, analgesic activities as studied in rats, ${ }^{3}$ and the presence of vitamins, essential and nonessential amino acids, minerals, enzymes, and saccharides make AV as good supplement and herb to treat various ailments. $^{28}$

To conclude, the quality of AV used by the consumer due to various times of cultivation and collection throughout the world play an important role to predict the actual amount of major therapeutic ingredients present in the plant. Similarly, the amount and dosage form of AV used is another important factor contributing toward the safe use of AV. The review article provided the latest clinical cases observed, and the factor responsible for $\mathrm{AV}$ toxicity. It is evident that $\mathrm{AV}$ may be fatal if used improperly, without proper guidance and in severe doses, however, a proper use under medical supervision can easily reduce all these hazards. It is well-known that no specific examination test is available to check or reveal the attack or adverse effects of any phytomedicines; ${ }^{29}$ however, a recent accurate history and use of proper histopathology tests may help control or handle such kind of situations. ${ }^{30,31}$ Even in most of the situations, no apparent symptoms are available, and no physical signs can be followed; however, IgG, anti-HBs as well as anti-HIV tests are the possible solution to detect such AV toxicity. Although supportive medication is used widely, in most of the cases, discontinuation of the herb also leads to patient recovery. The cases presented in the review also supports that "to stop the herb" worked in most of the cases for the patient to recover. ${ }^{15}$

\section{CONCLUSION}

$\mathrm{AV}$, as a medicinal plant possesses great respect for its content. Every plant, its extract or active ingredient may produce specific side effects or adverse effects which is commonly associated with any medications or normal dose. AV produces mild-to-severe range symptoms that can be treated by abrupt discontinuation. However despite its beneficial effects, AV can be too toxic under improper administration. Patients should be aware of proper doses and dosage of AV products. Simply, we recommend all $\mathrm{AV}$ consumers to take caution during consuming these products and to know the proper way of use, by asking their health-care providers.

\section{Financial support and sponsorship}

Nil.

\section{CONFLICTS OF INTEREST}

The authors declare no conflict of interest. 


\section{REFERENCES}

1. Surjushe A, Vasani R, Saple DG. Aloe vera: A short review. Indian J Dermato 2008;53(4):163

2. Rajeswari R, Umadevi M, Rahale CS, Pushpa R, Selvavenkadesh S, et al. Aloe vera: The miracle plant its medicinal and traditional uses in India. J Pharmacogn Phytochem 2012;1(4):118-24

3. Steenkamp V, Stewart MJ. Altmetric research article medicinal applications and toxicological activities of aloe. Products. J Pharma Bio 2012;45:411-20.

4. West BJ, Deng S. Ingredients other than noni may be culprits in acute hepatotoxicity in 14-year-old boy. J Pediatr Gastroenterol Nutr 2011;53:469-70.

5. Available from: https://www.livestrong.com/article/120262-aloe-vera-juice-sideeffects/.

6. Shelton RM. Aloe vera. Its chemical and therapeutic properties. Int J Dermatol 1991;30:679-83.

7. Boudreau MD, Beland FA. An evaluation of the biological and toxicological properties of aloe barbadensis (miller), aloe vera. J Environ Sci Health C Environ Carcinog Ecotoxicol Rev 2006;24:103-54.

8. Boudreau MD, Beland FA, Nichols JA, Pogribna M. Toxicology and carcinogenesis studies of a nondecolorized corrected whole leaf extract of aloe barbadensis miller (aloe vera) in F344/N rats and B6C3F1 mice (drinking water study). Nat Toxicol Program Tech Rep Ser 2013;1-266.

9. Unlu A, Nayir E, Hale AY, Kirca O, Ozdogan M. Aloe vera and cancer. Turk J Oncol 2016;31:69.

10. Radha MH, Laxmipriya NP. Evaluation of biological properties and clinical effectiveness of aloe vera: A systematic review. J Tradit Complement Med 2015;5:21-6.

11. Hong IT, Cha JM, Ki HJ, Kwak MS, Yoon JY, Shin HP, et al. Small bowel obstruction caused by aloe vera bezoars: A case report. Korean J Gastroenterol 2017;69:312-5.

12. Parlati L, Voican CS, Perlemuter K, Perlemuter G. Aloe vera-induced acute liver injury: A case report and literature review. Clin Res Hepatol Gastroenterol 2017;41:e39-42.

13. Hervás-García JV, Montané E, Serrado-Iglesias A, Ramo-Tello C. Toxic hepatitis after concomitant interferon beta and aloe vera treatment in a patient with multiple sclerosis: A case report. Neurologia 2017;32:546-7.

14. Lee J, Lee MS, Nam KW. Acute toxic hepatitis caused by an aloe vera preparation in a young patient: A case report with a literature review. Korean J Gastroenterol 2014;64:54-8

15. Rabe C, Musch A, Schirmacher P, Kruis W, Hoffmann R. Acute hepatitis induced by an aloe vera preparation: A case report. World J Gastroenterol 2005:11:303-4.
16. Yang HN, Kim DJ, Kim YM, Kim BH, Sohn KM, Choi MJ, et al. Aloe-induced toxic hepatitis. J Korean Med Sci 2010;25(3):492-5.

17. Bottenberg MM, Wall G

18. C, Harvey RL, Habib S. Oral aloe vera-induced hepatitis. Ann Pharmacother 2007:41:1740-3

19. Ferreira M, Teixeira M, Silva E, Selores M. Allergic contact dermatitis to aloe vera. Contact Dermatitis 2007;57:278-9.

20. Surjushe A, Vasani R, Saple DG. Aloe vera: A short review. Indian J Dermatol 2008:53:163-6.

21. Brown AC. Liver toxicity related to herbs and dietary supplements: Online table of case reports. Part 2 of 5 series. Food Chem Toxicol 2017;107:472-501.

22. Yang HN, Kim DJ, Kim YM, Kim BH, Sohn KM, Choi MJ, et al. Aloe-induced toxic hepatitis. J Korean Med Sci 2010;25:492-5.

23. Avijgan $\mathrm{M}$, Alinaghian $\mathrm{M}$, Esfahani $\mathrm{MH}$. Aloe vera gel as a traditional and complementary method for chronic skin burn: A case report. Adv Infect Dis 2017;7:19-25

24. Chugh BS, Bansal NA, Garg SC, Koul ML. Safety Evaluation of Aloe Vera Pulp Aqueous Extract Based on Histoarchitectural and Biochemical Alterations in Mice. NISCAIR Online Periodicals Repository. August, 2011.

25. McAnalley, et al. United States Patent (19). Patent Number:45:5;106:616; 21 April, 1992.

26. Dal'Belo SE, Gaspar LR, Maia Campos PM. Moisturizing effect of cosmetic formulations containing aloe vera extract in different concentrations assessed by skin bioengineering techniques. Skin Res Technol 2006;12:241-6.

27. Djuv A, Nilsen OG, Steinsbekk A. The co-use of conventional drugs and herbs among patients in Norwegian general practice: A cross-sectional study. J Int Soc Comp Med Res 2018;???:???

28. Singh B, Mohan R, Maurya A, Mishra G. Phytoconstituents and biological consequences of a focused review. Asian J Pharm Pharmacol 2018:4:17-22.

29. Vogler BK, Ernst E. Aloe vera: A systematic review of its clinical effectiveness. Br J Gen Pract 1999;49:823-8.

30. Upadhyay A, Tuenter E, Ahmad R, Amin A, Exarchou V, Apers S, et al. Kavalactones, a novel class of protein glycation and lipid peroxidation inhibitors. Planta Med 2014:80:1001-8.

31. Ahmad A, Upadhyay A, Ahmad M, Pieters L. Antioxidant, antliglycation and antimicrobial activities of Ziziphus oxyphylla and Cedrela serrata extracts. Eur $J$ Med Plants 2013;3:520-9

32. Ahmad R, Ahmad M, Mehjabeen, Jahan N. Phytochemical screening and antioxidant activity of the two plants Ziziphus oxyphylla edgew and Cedrela serrata royle. Pak J Pharm Sci 2014;27:1477-82.

\section{GRAPHICAL ABSTRACT}

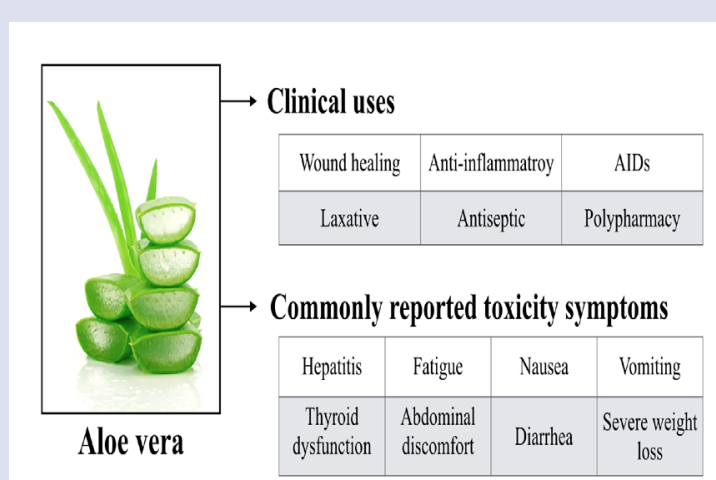

\section{SUMMARY}

- $A V$ is a famous plant used throughout the world for therapeutic as well as nontherapeutic purposes, i.e., cosmetics. The plant is known as a polypharmacy and has been reported with enormous biologically active constituents ranging from amino acids, vitamins, anthraquinone glycosides, and phenolic compounds. Although the plant have a widespread use, however if used in improper dosage form, severe doses for long time, and without the medical supervision of a health professional may lead to hepatitis, kidney disease, and allergy,

Cite this article: Ibrahim AM, Al Sadah H, Ahmad R, Ahmad N, Naqvi AA. Clinical uses and toxicity of Aloe vera: An evidence-based comprehensive retrospective review (2007-2017). Pharmacog J. 2019;11(2):424-8. 